\title{
DEVELOPMENTAL PATTERNS IN STEM PRIMARY XYLEM OF WOODY RANALES. I. SPECIES WITH UNILACUNAR NODES ${ }^{1}$
}

\author{
David H. Benzing
}

Department of Botany, University of Michigan, Ann Arbor ${ }^{2}$

\author{
A $\quad B \quad S \quad T \quad R \quad A \quad C \quad T$
}

\begin{abstract}
Patterns of protoxylem strands in vegetative stems of 11 species representing eight families of woody Ranales are illustrated and discussed. Primary vascular systems of many species examined tend to be pseudosiphonostelic. Protoxylem tissue, however, is discontinuous and consists of discrete strands which develop basipetally. The author assumes that data pertaining to the morphology of these protoxylem strand patterns can be significant in determining phylogenetic relationships among ranalean families and between these and higher angiosperms. The value of the primary vascular system in past taxonomic investigations is also considered. Results of this study indicate that the protoxylem strand patterns of 11 woody ranalean species are diverse even though the species are characterized by identical phyllotaxis and nodal structure.
\end{abstract}

POPUlar CONCEPTS of stelar structure and evolution in the Pteropsida have led botanists to believe that the primary vascular system in seed plants is a modified "fern type" consisting of an anastomosing, cylindrically organized system of collateral or bicollateral vascular bundles. Jeffrey's studies and proposals (1917) on stelar evolution solidified the classical concept of the vascular cylinder to such an extent that the nature of the seed plant primary vascular system and its possible systematic value seem to have been largely ignored or misunderstood by many plant morphologists (Philipson and Balfour, 1963). In the following comparative analysis one aspect of the primary vascular system of vegetative stems, the patterns of protoxylem strands, was analyzed in an attempt to discover information of systematic value. Eleven species of woody Ranales characterized by unilacunar nodes were investigated.

Materials AND METHODS-All shoots were collected while in a state of active vegetative growth (see Table 1). Specimens were immediately fixed in formalin-acetic acid-alcohol solution (FAA) or in $70 \%$ ethyl alcohol. Shoots were then dehydrated, embedded in paraffin, serially

1 Received for publication 1 June 1966

This work was based on a dissertation submitted to the Graduate School of The University of Michigan in partial fulfillment of the requirements for the degree Doctor of Philosophy.

Sincere appreciation is extended to Dr. Charles B. Beck and Dr. Warren H. Wagner, Jr., for their advice during the course of this research and in the preparation of this manuscript. Thanks are also extended to the collectors of much of the plant material utilized in this investigation.

2 Present address: Department of Biology, Oberlin College, Oberlin, Ohio. sectioned, and stained with a safranin-fast green combination according to traditional methods.

Since many woody ranalean species exhibit at least a tendency toward pseudosiphonostelic stem anatomy (a continuous ring of procambium, primary phloem and later, primary xylem close behind the apex), the only primary vascular tissue often present in a circumferentially discontinuous state for any length of the stem is the protoxylem.

In the literature numerous modes of description and systems of terminology have been used to describe patterns of primary vascular systems. The resulting diversity of treatments often makes comparisons between the works of different authors difficult or impossible. To avoid additional confusion the author points out that vascular patterns described herein are based on observations of protoxylem strands only, even in those species possessing discrete primary vascular strands, i.e., species with eustelic stem anatomy (see Table 1). Although patterns are then comparable within this study, these patterns cannot be directly compared to vascular patterns based on the configuration of primary vascular strands (strands made up of primary xylem and primary phloem). The latter mode of description is the most common in the literature, but it can only be applied to eustelic vascular systems.

In order to reconstruct the configuration of the protoxylem strand pattern as it exists in the intact axis, the following techniques were applied. The stained, serial, transverse sections of each shoot were examined microscopically until a point was located just above the area where the protoxylem strands could no longer be traced because of the occurrence of interfascicular cambial activity or the production of a more or less

The Journal for July (54: 663-804) was issued 1 August 1967 American Journal of Botany, Vol. 54: No. 7, 1967 
AMERICAN JOURNAL OF BOTANY

[Vol. 54

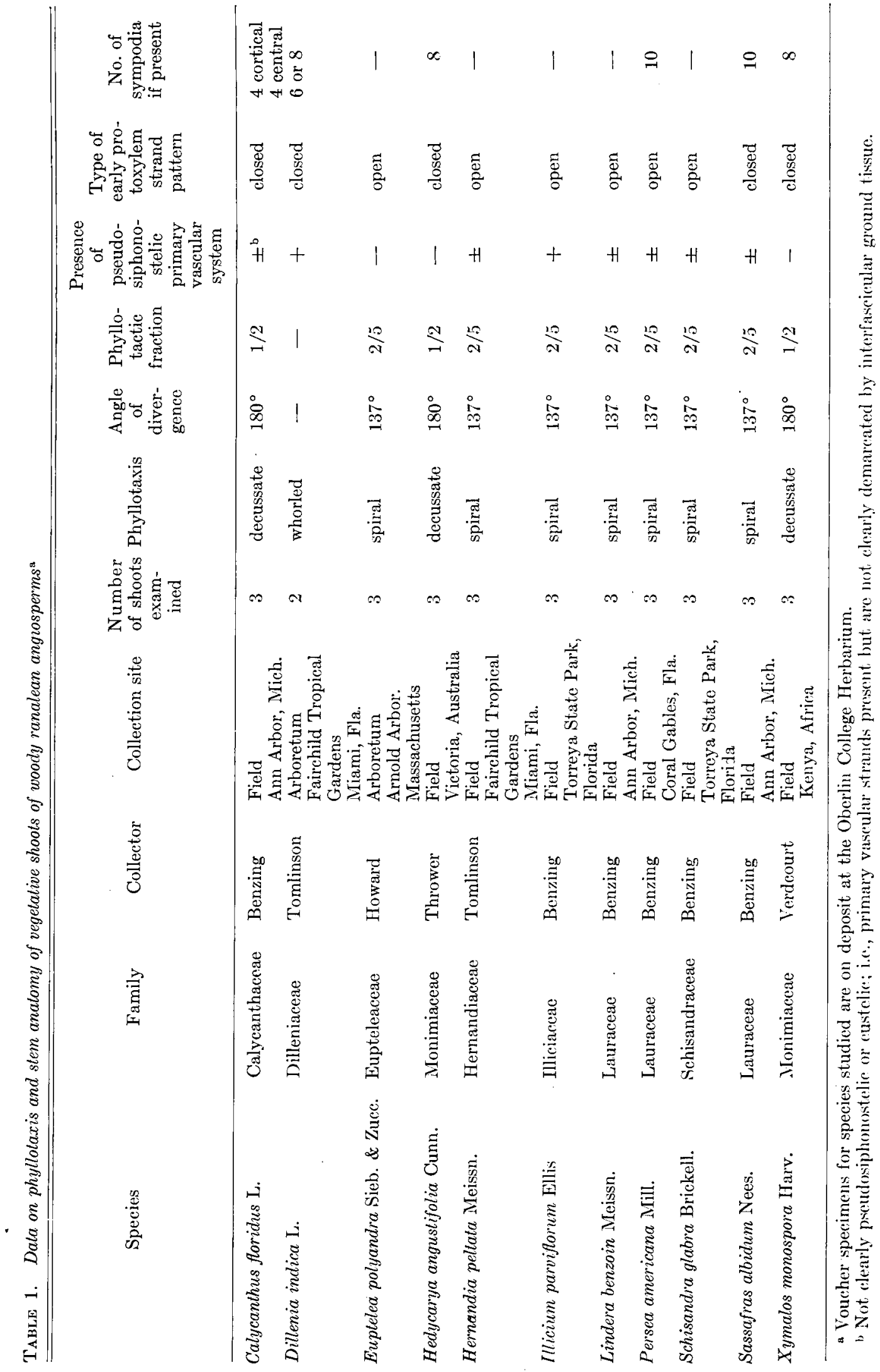


continuous ring of late primary xylem. In this section one protoxylem strand was chosen arbitrarily and numbered " 1. " Proceeding in a clockwise direction from this point, the other protoxylem strands in the vascular cylinder were numbered " 2 ," " 3 ," etc. The locations and numbers of each strand in this cross-section were then indicated from left to right across the baseline of a sheet of small-interval graph paper. Moving toward the apex of the shoot, another section was examined and the location of each strand was again recorded on the next higher horizontal line on the graph paper. Vertical lines were then drawn connecting the plotted points of identical strands, thus simulating the upward path of all strands traversing the interval between the two sections observed. This technique is similar to that utilized by Kumari (1963). Distances between successive serial sections examined in the lower portions of the shoots were considerably greater than the intervals near the shoot apex where every section was observed.

By using this technique it was possible to reconstruct the pattern of protoxylem strands as they would appear if the stem were split open along one side and spread out flat with the inner surface of the primary vascular system facing the observer. Diagrams obtained in this manner show the following features of the protoxylem strand pattern: (1) the upward course of the protoxylem strands from an arbitrarily chosen level, (2) the points of division and fusion of these strands, (3) a rough approximation of the lateral distances between adjacent strands, and (4) the points of departure of strands to leaf primordia from the vascular cylinder. Quantitative data pertaining to the phyllotaxis and strand patterns of species investigated are presented in Table 1.

Terminologr-The structural configuration of the protoxylem strand pattern of stems of these plants is closely related to their phyllotaxis. Discussion of strand patterns, therefore, is greatly aided by the employment of certain phyllotactic terms. A few of these terms and others are defined below.

Angle of divergence-the smallest fraction of the circumference of the stem which separates the points of origin of two successively initiated leaves.

Sympodium - a longitudinal, branching protoxylem strand in the vegetative stem. Two basic types are recognized: (a) scorpioid sympodium from which the branch strands arise on both sides, and (b) helicoid sympodium from which the branch strands arise only on one side.

Median leaf trace strand-a strand constituting the protoxylem portion of a median leaf trace.

Lateral leaf trace strand - a strand constituting the protoxylem portion of a lateral leaf trace.
Cathodic strand divergence - a term given to a protoxylem strand that diverges from a sympodium or another strand in the same direction as the ontogenetic spiral.

Anodic strand divergence-a term given to a protoxylem strand that diverges from a sympodium or another strand in the opposite direction of the ontogenetic spiral.

Closed strand pattern - a strand pattern made up of sympodia or leaf trace strands that fuse or are interconnected along the length of the stem (not to be confused with Dormer's [1945] open and closed primary vascular strand patterns).

Open strand pattern-a strand pattern made up of sympodia or leaf trace strands that do not regularly fuse or interconnect along the length of the stem.

Leaf gap-a nonvascular region located between vascular portions in the vascular cylinder directly above the diverging leaf trace strands.

Illicium parviflorum (Illiciaceae)-This plant possesses the simplest protoxylem strand pattern of all eleven species studied. A diagrammatic representation of its strand pattern is illustrated in Fig. 1. Figures 2-13 represent a series of crosssections cut through the same shoot in an acropetal direction. This series begins just above the level of the 16th oldest leaf on the axis and proceeds to a point close below the shoot apex. The strand pattern of $I$. parviflorum is an open type made up of five groups of strands, each of which vascularizes leaves of one of the five parastichics visible in Fig. 13. Every fifth leaf along the ontogenetic spiral belongs to the same parastichy. Approximately two complete turns are made around the axis in linking two superposed leaves on the stem. The $2 / 5$ th phyllotactic fraction observed (see Table 1) for I. parviflorum has then a direct morphological and anatomical correlation. The angle of divergence approximates the so-called limiting angle (approximately $137 \mathrm{deg}$ ) of the Fibonacci series (Church, 1920).

$\Lambda$ sympodial system was not observed in any of the three shoots of $I$. parviflorum studied. Below leaf 20, in addition to the protoxylem strands and the early initiated continuous ring of primary phloem, metaxylem and possibly some secondary xylem develop to a point where a solid ring of xylem and phloem exists, broken only by a single leaf gap at each node. Distinction between primary xylem and early secondary xylem is particularly difficult to establish in this species. The continuous ring of xylem which unites the previously discrete protoxylem strands in the genus Illicium has been commented on by other workers (Bailey and Nast, 1948).

The basipetal nature of protoxylem development in $I$. parviflorum is also indicated in Fig. 1. Such basipetal differentiation has been reported for a variety of angiosperms (Esau, 1965a). Leaf traces of procambium to leaf primordia were 


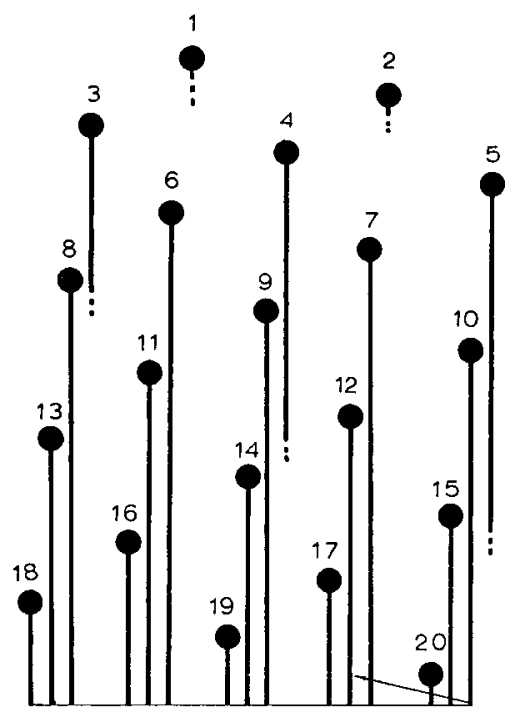

1

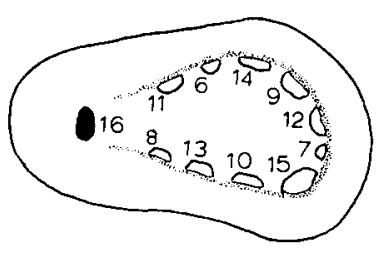

2

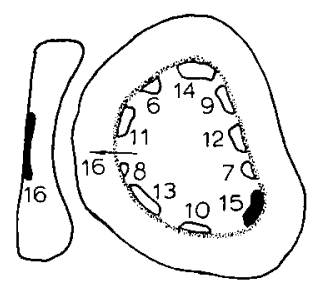

4

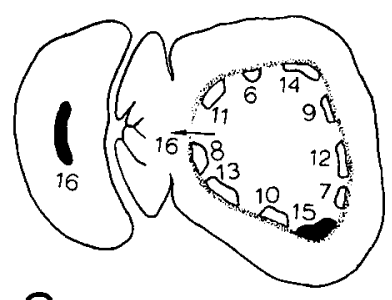

3

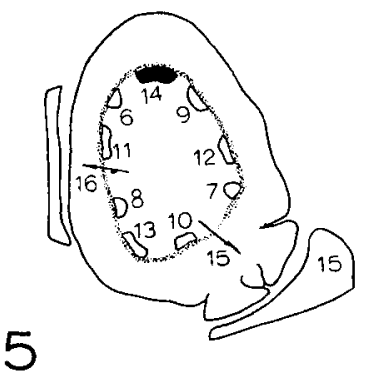

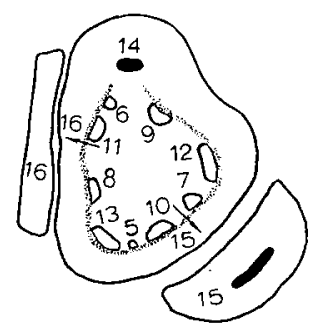

6
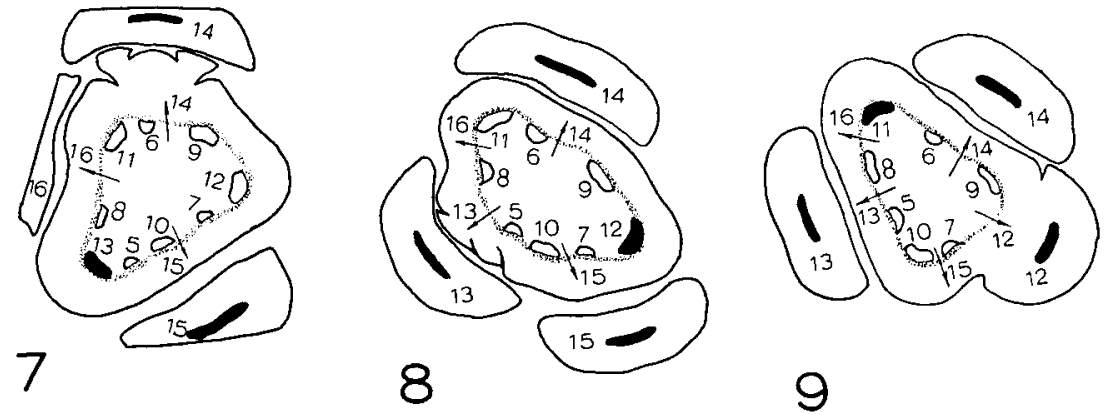

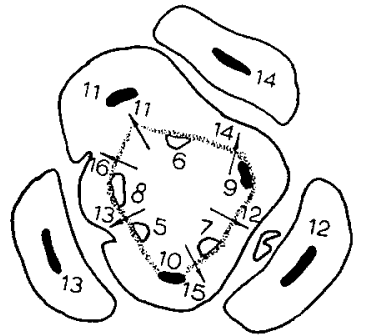

10

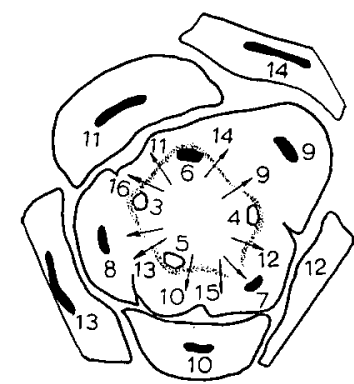

11

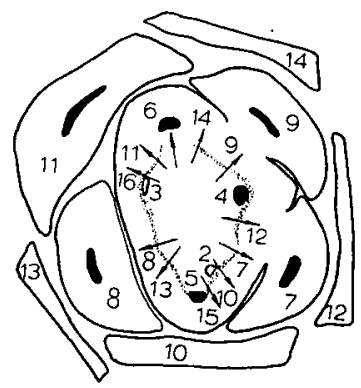

12

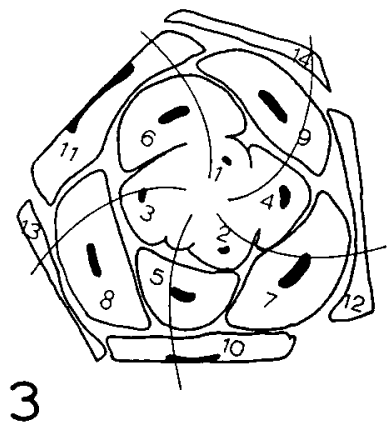

13

Fig. 1-13.-Fig. 1. The early protoxylem strand pattern of Illicium parviflorum. Dark lines indicate strands containing mature primary xylem elements. Dotted lines depict regions where basipetally differentiating protoxylem cells are incompletely developed. The arrow indicates the direction of the ontogenetic spiral. Points representing xylem strand departures to leaves are indicated by black circles and are numbered successively from the youngest to the oldest. - Fig. 2-13. A series of cross sections arranged in ascending order from the shoot of Illicium parviflorum illustrated in Fig. 1. 
detected above the youngest leaf primordia recorded in Fig. 1, but they were not recorded on the diagram. Leaf-trace strands to primordia 3 , 4 , and 5 show progressive stages in the basipetal differentiation of the early protoxylem elements. All older strands are continuous with the complete ring of xylem tissue present at the level just below the insertion of leaf 20 . All three shoots of Illicium parviflorum examined were found to possess identical strand patterns.

Schisandra glabra (Schisandraceae)-Vegetative shoots of this species possess a protoxylem strand pattern somewhat similar to that of Illicium parviflorum. However, in this species an additional leaf-trace strand occurs closely associated with each side of the median leaf-trace strand (Fig. 14). Thus, the nodal anatomy is the three-trace, unilacunar type previously reported for Schisandra (Bailey and Nast, 1948). Below the 15th node a solid cylinder of xylem develops as in Illicium parviflorum, obscuring the details of the discrete protoxylem strands apparent in the younger region of the stem.

Although three strands enter each leaf in Schisandra glabra, the five-strand groups found in the open system of Illicium parviflorum can be recognized in this species also. In Schisandra glabra, as in Illicium parviflorum, strands within these five-strand groups have not been observed to join to form sympodia. Here, as in the previous species, each of the five-strand groups vascularizes one of the five parastichies visible at the level of the shoot apex. The phyllotactic fraction of $2 / 5$ and angle of divergence of $137 \mathrm{deg}$ are identical to those of $I$. parviflorum (Table 1).

Schisandra glabra is characterized by basipetal differentiation of early protoxylem. Differentiation of the first tracheary elements occurs in the lateral median strands somewhat later than in the central one at a given level.

Euptelea polyandra (Eupteleaceae)-The protoxylem strand pattern in vegetative shoots of $E$. polyandra appears to be an elaboration of the types found in Schisandra glabra and Illicium parviflorum. Instead of one or three strands entering a single leaf, usually five, and occasionally seven to nine, small strands depart from the vascular cylinder through a single leaf gap at each node.

Inspection of the lower part of the diagram (Fig. 15) indicates that strands fail to fuse with other strands making up any of the five recognizable strand groups; hence, the pattern is open and sympodia are lacking. Five parastichies corresponding to strand groups are observed in a cross-section of the shoot tip of Euptelea polyandra as in the previously considered species. The phyllotactic fraction and angle of divergence are identical with those of the previously described species.

In two of the three shoots of $E$. polyandra investigated, each pair of strands lateral to the central strand vascularizing a node arise by division of a single strand below. The point of this division in the vascular cylinder varies with the node. Thus the five strands in evidence at departure from the vascular cylinder originate from three strands farther down the axis. In a third shoot the number of strands present at the nodes exceeded five and these five strands were found to remain distinct as far as they could be followed downward. The latter shoot consisted of fewer nodes than the other two, and the possible origin of the increased number of strands from fewer strands below could not be ascertained.

Hernandia peltata (Hernandiaceae)-The protoxylem strand pattern of Hernandia peltata is illustrated in Fig. 16. This system appears to be an elaboration of the Schisandra glabra-Euptelea polyandra type. Here a large and irregular number of small strands depart from the vascular cylinder at each node. These strands usually remain discrete down the axis. The phyllotaxis and angle of divergence of Hernandia peltata are like those of the previous three species considered.

Lindera benzoin, Persea americana, Sassafras albidum (Lauraceae)-Figure 17-19 illustrate the strand patterns of these three lauraceous species. The strand pattern of Lindera benzoin is nearly jdentical with that pattern described earlier for Schisandra glabra (Fig. 14) with the exception of an occasional node which is furnished by leaf-trace strands arising from both sides of the leaf gap five nodes below. This bipartite origin of the protoxylem supply to each leaf is even more common in Sassafras albidum (Fig. 18) and occurs without exception in Persea americana (Fig. 19). Protoxylem vasculature of each node of $P$. americana consists of two discrete strands arising from the two helicoid sympodia supplying the leaf five nodes below. These two strands then fuse and the resulting single strand divides to form three leaf-trace strands which depart to the young leaf from a single gap in the vascular cylinder; hence, every fifth leaf along the ontogenetic spiral is vascularized by the

The numbered, open and black circles located on the inside of the stippled, continuous ring of procambium and primary phloem are protoxylem strands. These xylem strands are numbered according to the age of the leaf they vascularize. Solid black protoxylem strands represent the xylem of leaf traces and leaf bundles during or after the same depart from the vascular cylinder. Numbered arrows represent former positions of departed protoxylem strands. The five curved lines in Fig. 13 represent parastichies. 

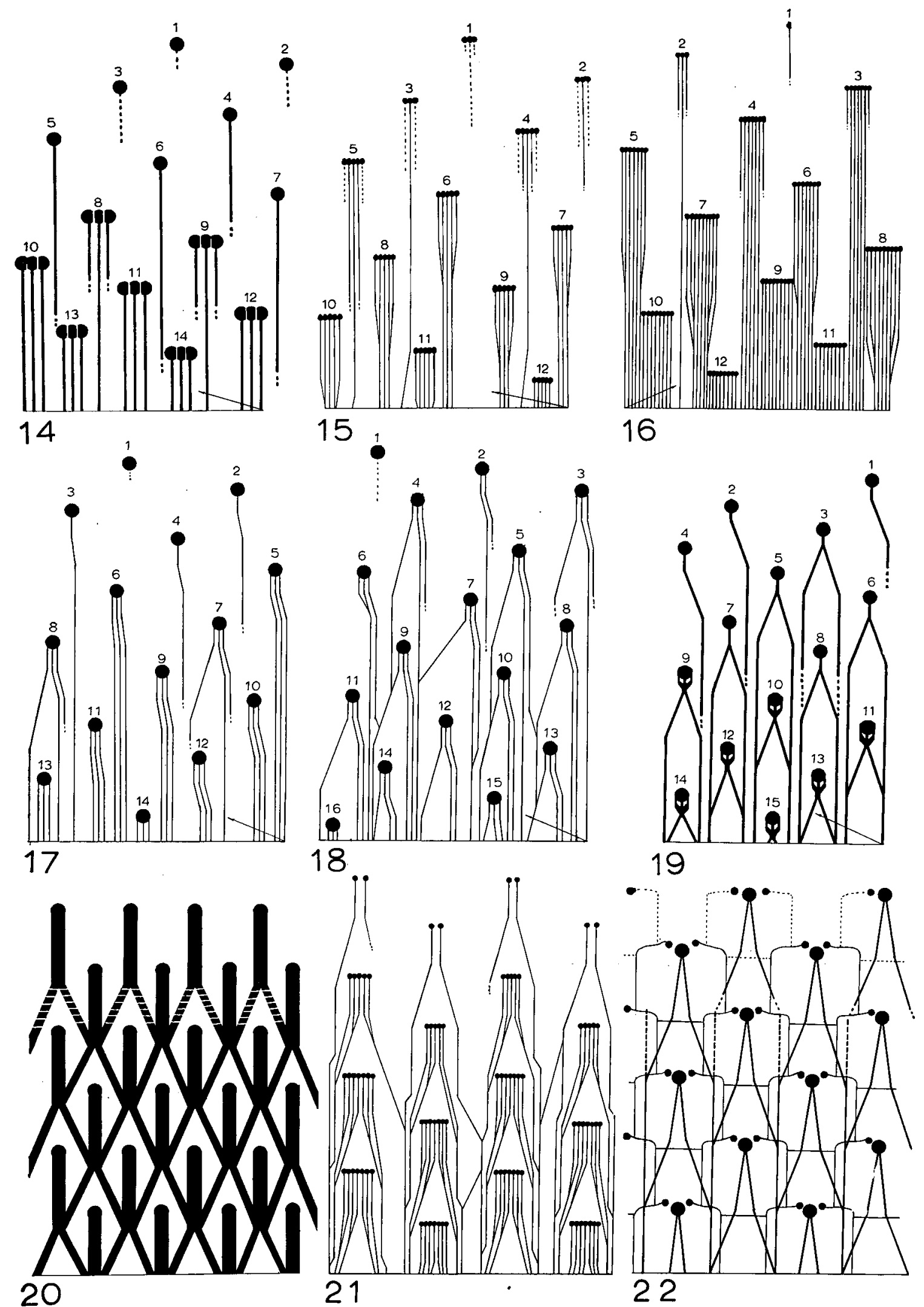

18
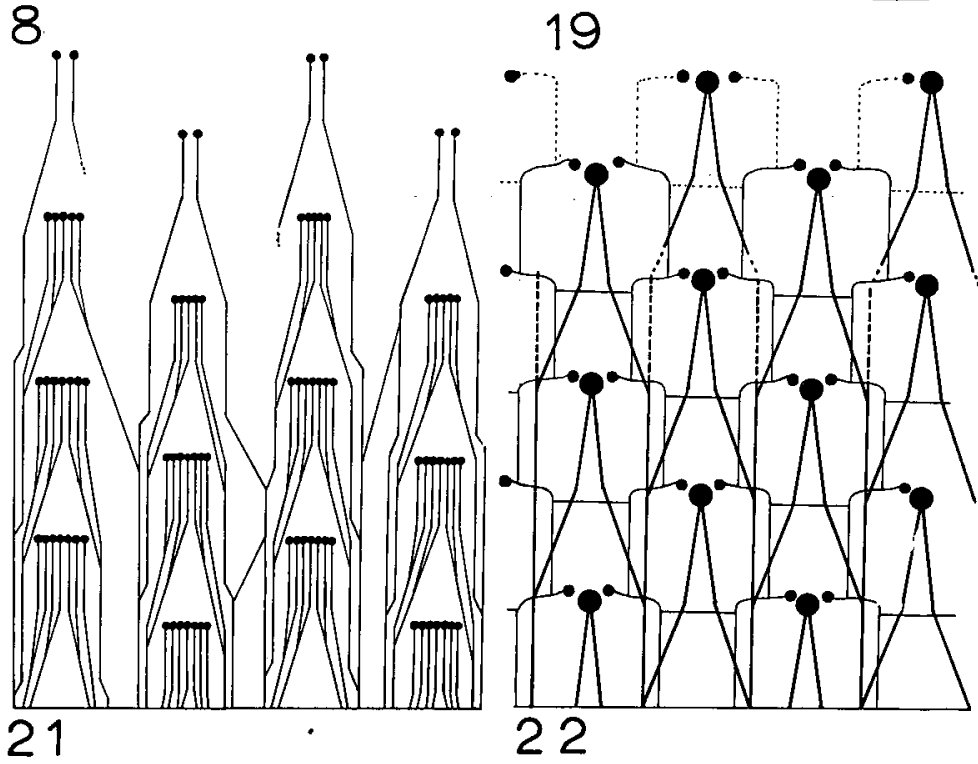
same pair of helicoid sympodia. Although regular fusion occurs between the two sympodia of each of the five sympodial pairs, the pairs remain discrete and the strand pattern is open. All three species possess three-trace, unilacunar nodal anatomy regardless of strand pattern differences discussed above. The pattern of Sassafras albidum is transitional between the simple pattern of Lindera benzoin and the more elaborate pattern of Persea americana.

The angle of divergence in all three lauraceous species is approximately $137 \mathrm{deg}$ and the phyllotactic fraction is $2 / 5$. Maturation of early protoxylem follows the same order as that of Schisandra glabra except where the strands entering a leaf result from the fusion of two strands which arise on each side of the leaf gap five nodes below. In these situations the basipetal differentiation of the early protoxylem of the leaf trace strand occurs first on the side closest to the previously initiated leaf primordium (see Fig. 19).

Dillenia indica (Dilleniaceae)-This plant, unlike those species considered above, is characterized by whorled phyllotaxis. Robust shoots bear four leaves at each node, whereas stems of smaller diameter bear three leaves per whorl. Each leaf is vascularized by a single broad trace.

The protoxylem strand pattern of a shoot of the former type is depicted in Fig. 20, the heaviness of the lines suggesting the broad nature of the strands. The entire pattern consists of eight scorpioid sympodia which follow a regular sinuous path along the axis. Where two adjacent scorpioid sympodia are closest to one another laterally, branches from each fuse into a single, broad median strand. Hence, the direction of strand divergence along each sympodium alternates at each node. The pattern thus has a regularly reticulate, or closed, architecture. Shoots with whorls of three leaves possess a similar strand pattern made up of six sympodia instead of eight.

Hedycarya angustifolia, Xymalos monospora (Monimiaceae)--These species exhibit the decussate phyllotaxis characteristic of their family. The nodal anatomy of the two species is similar in being complex and consisting of seven or more leaf-trace strands departing from the vascular cylinder through a single, broad gap. The strand pattern of Hedycarya angustifolia and Xymalos monospora (Fig. 21) indicates that each of the four orthostichies of the decussate shoot is vascularized by one pair of helicoid sympodia. Strand patterns of these two species close as fusions of adjacent pairs of helicoid sympodia occur. Money, Bailey and Swamy (1950) have suggested that the two-trace, unilacunar node is basic in this family, and nodal anatomy of this type is, in fact, found in certain genera of the Monimiaceae (sensu lato) such as Trimenia and Piptocalyx. They propose that the more elaborate nodal anatomy of genera such as Hedycarya and $X y m a l o s$ arose through proliferation of the two traces of the ancestral type. The protoxylem strand pattern in the youngest nodes of Hedycarya anyustifolia and Xymalos monospora (Fig. 21) may reflect this possible ancestry.

Calycanthus floridus (Calycanthaceac)-The presence of an unusual cortical system of inverted (i.e., endophloically collateral) vascular bundles in both genera of the Calycanthaceae has interested plant morphologists for some time. Several papers discussing the nature and significance of this system have been published over the last 50 years (Quinlan, 1920; Boureau, 1946; I'ahn and Bailey, 1957; Balfour and Philipson, 1962). In most cases, however, only a short longitudinal portion of the primary vascular system has been illustrated. Figure 22 represents the protoxylem strand pattern of Calycanthus floridus from its initiation just below the shoot apex to a point where secondary xylem and/or late protoxylem, xylem and metaxylem obscure the detail of the individual protoxylem strands in the central vascular cylinder. As reported by Fahn and Bailey (1957), the cortical system furnishes two lateral leaf traces to each leaf and is not connected with the central vascular system at any point along its length. The cortical system of bundles is made up of four scorpioid sympodia interconnected by vascular bridges in a regular manner. The origin of the cortical system in seedlings of the Calycanthaceae is discussed by Balfour and Philipson (1962).

The central vascular cylinder tends to be pseudosiphonostelic and only the early protoxylem tissue is discontinuous around the vascular cylinder in young shoots. The single, median strand contributed to every leaf by this system is formed by the fusion of two strands arising from two adjacent scorpioid sympodia. Direction of bundle and early protoxylem strand divergence from scorpioid sympodia of cortical and central systems respectively alternates at each node. Both central and cortical systems then form closed patterns.

The first tracheary cells to differentiate in subapical stem tissue are located in the central vascular cylinder. Maturation of early primary

Fig. 14-22.-Fig. 14. Early protoxylem strand pattern of Schisandra glabra.-Fig. 15. Euptelea polyandra.-Fig. 16. Hernandia pellata.-Fig. 17. Lindera benzoin.-Fig. 18. Sassafras albidum.-Fig. 19. Persea americana.-Fig. 20. Dillenia indica.-Fig. 21. Xymalos monospora.-Fig. 22. Calycanthus floridus. In Fig. 22 thick lines represent the central system of xylem strands, and thin lines represent the cortical bundles of xylem and phloem. 
xylem in the cortical bundles occurs after tracheary elements have appeared in the central cylinder at the same level.

Discussion-Jeffrey's (1917) ideas and the classical concept of the angiosperm vascular cylinder suggest that morphological patterns of the primary vascular tissues of stems of seed plants are uniform and of little use in systematic correlation. Such an attitude, combined with the technical difficulties of obtaining information on large numbers of primary vascular tissue patterns, probably accounts for the little interest and paucity of published data on the primary vascular system of vegetative stems in angiosperms.

A second interpretation of angiosperm primary vascular anatomy, which is neither based on hypothetical evolutionary origins nor restricted to mature steles as is Jeffrey's, recognizes that the primary vascular system of flowering plant stems is often composed of varying numbers of independent and discrete vascular bundles or protoxylem strands with or without interconnections. These bundles or strands follow definite and distinctive pathways through the stem axis. The latter interpretation appears closer to the truth, and the real state of affairs is much more complex than the simple conceptualization suggested by Jeffrey's purely conjectural hypothesis. Primary vascular cylinders composed of discrete vascular tissues or bundles either at maturity or during development offer the possibility of considerable pattern diversity and, hence, could be a source of data of systematic value (Philipson and Balfour, 1963).

As a result of the second interpretation of the vascular system and numerous ontogenetic investigations, some workers (see Esau, 1965b) have described the primary vascular system of stems of seed plants as an aggregation of foliar traces whose nature and position in the axis are in part determined by the particular phyllotaxis of the species. This interpretation has gained support from studies of the organizational properties of isolated shoot species grown in vitro and surgical manipulation of shoot tips in situ (Wetmore and Wardlaw, 1951). These studies indicate that the shoot apex itself is morphogenetically self directing and determines the positions of leaf primordium initiation. Leaf primordia may then control the development of the primary vascular system below as demonstrated by auxin induction studies of Jacobs and Morrow (1957).

Another view states that the organization of the primary vascular cylinder and the loci of leaf primordia initiation are determined by inductive factors arising from more mature regions of the stem. Acropetal development of primary phloem and procambium seem to support this theory.

Regardless of the inductive mechanisms, the architecture of at least some primary vascular tissues in higher plant stems is often specific for the species and can be different among plants exhibiting identical phyllotaxis and nodal anatomy. This is certainly borne out in the 11 ranalean species considered here. It is reasonable, therefore, to assume that patterns of discrete vascular bundles, or in pseudosiphonostelic forms of discrete protoxylem strands, can be utilized for taxonomic purposes to the same advantage as are other commonly used morphological data.

In an analysis of the Leguminosae, Dormer (1945) found a high degree of correlation between primary vascular bundle patterns (apparently his species were eustelic) of vegetative stems and certain floral and vegetative character states. He proposed that the so-called "open acacian" vascular pattern is primitive in the family and is associated with woodiness, and the more complex, "closed" patterns are derived and often correlated with the derived (within the family) herbaceous plant body. Bisalputra (1962) made a similar analysis of the Chenopodiaceae and also found correlation between vegetative shoot architecture and other primitive and advanced character states in vegetative and floral structures. More recently Ezelarab and Dormer (1963), after an extensive survey of the Ranunculaceae, concluded that the primary vascular system of stems is of value in taxonomic analysis of this family.

Examination of the protoxylem strand pattern of eleven woody ranalean angiosperms with unilacunar nodes reveals much diversity in these patterns, even among species with identical phyllotaxis. The possible taxonomic significance of these patterns and of patterns in woody Ranales with trilacunar and multilacunar nodes will be discussed in a subsequent paper.

\section{LITERATURE CITED}

BalleY, I. W., AND C. G. Nast. 1948. Morphology and relationships of Illicium, Schisandra and Kadsura. I. Stem and leaf. J. Arnold Arbor. 29: 77-89.

Balfour, E. E., ANd W. R. Philipson. 1962. The development of the primary vascular system in certain dicotyledons. Phytomorphology 12: 110-143.

Bisalputra, T. 1962. Anatomical and morphological studies in the Chenopodiaceae. II. The primary vascular system and nodal anatomy. Austral. J. Bot. 10: $13-24$

Boureau, E: 1946. L'evaluation vasculaire du Calycanthus floridus L. (actuel: Calycanthacées) et l'explication du systéme vasculaire du Zygopteris locatti B. R. (Filicale palaeozoique; zygopteridées). Bull. Mus. Hist. Nat. Paris II. 18: $440-447$.

Church, A. H. 1920. On the interpretation of phenomena of phyllotaxis. Oxford University Press, London.

DORMER, K. J. 1945. An investigation of the taxonomic value of shoot structure in angiosperms with special reference to Leguminosae. Ann. Bot. 9: 141-153. 
Esau, K. 1965a. Vascular differentiation in plants. Holt, Rinehart and Winston, New York. - 1965b. Plant anatomy. 2nd ed. John Wiley and Sons, Inc., New York.

Ezelarai, G. E., and K. J. Dormer. 1963. The organization of the primary vascular system in the Ranunculaceae. Amn. Bot. 27: 23-38.

Fahn, A., ANd I. W. Baitey. 1957. The nodal anatomy and the primary vascular cylinder of the Calycanthaceae. J. Arnold Arbor. 38: 107-117.

Jacons, W. P., AND I. B. Morrow. 1957. A quantitative study of xylem development in the vegetative shoot apex of Coleus. Amer. J. Bot. 44: 823-842.

JEFFreY, E. C. 1917. The anatomy of woody plants. University of Chicago Press.

KumarI, G. K. 1963 . The primary vascular system of gymnosperms. Ph.D. thesis. University of Michigan, Ann Arbor.

Money, L. L., I. W. BaIley, and B. G. Swamy. 1950. The morphology and relationships of the Monimiaceae. J. Arnold Arbor. 31: 372-404.

Philipson, W. R., And E. E. Balfour. 1963. Vascular patterns in dicotyledons. III. Anatomy of the stem of Calycanthaceae. Trans. Roy. Soc. Edinb. 52: $517-530$.

QUinian, C. E. 1920. Contributions towards a knowledge of the anatomy of the lower dicotyledons. III. Anatomy of the stem of Calycanthaceae. Trans. Roy. Soc. Edinb. 52: 517-530.

Wetmore, R. H., and C. W. Wardlaw. 1951. Experimental morphogenesis in vascular plants. Ann. Rev. Plant Physiol. 2: 269-292.

Amer. J. Bot. 54(7): 813-820. 1967.

\title{
DEVELOPMENTAL PATTERNS IN STEM PRIMARY XYLEM OF WOODY RANALES. II. SPECIES WITH TRILACUNAR AND MULTILACUNAR NODES ${ }^{1}$
}

\author{
David H. Benzing \\ Department of Botany, University of Michigan, Ann Arbor²
}

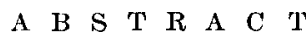

\begin{abstract}
Patterns of early protoxylem strands in vegetative stems of 16 species of woody Ranales representing nine families with trilacunar or multilacunar nodes are illustrated and discussed. The order of differentiation of first protoxylem in all examined species is basipetal. Open, protoxylem strand patterns are more common than closed patterns in these taxa and 11 other woody ranalean species with unilacunar nodes. Protoxylem strand patterns in woody Ranales are diverse, even among species with identical phyllotaxis and nodal anatomy. Pattern similarities of possible taxonomic significance exist, however, between some species of the Annonaceae and Myristicaceae, Hernandiaceae and Lauraceae, and the Canellaceae and Winteraceae. The general diversity of strand patterns in woody Ranales may reflect the high degree of evolutionary isolation among ranalean families. Results of these investigations on stem anatomy of woody Ranales indicate that the two-trace, unilacunar node is probably not primitive in the Angiospermae. Evidence from this study and others suggests that the primitive node in the Angiospermae, and possibly in all seed plants, is one-trace, unilacunar or trilacunar. Two-trace, unilacunar nodal anatomy of the Clerodendron type may have evolved in conjunction with the evolution of decussate phyllotaxis. The protoxylem strand patterns of Illicium and/or Drimys are probably the most primitive of those described in the woody Ranales.
\end{abstract}

IN A PRECEDING STUDY (Benzing, 1967) patterns of protoxylem strands in vegetative shoots of 11 woody ranalean species characterized by unilacunar nodal anatomy were described. These

${ }^{1}$ Received for publication 1 June 1966.

This work was based on a dissertation submitted to the Graduate School of The University of Michigan in partial fulfillment of the requirements for the degree Doctor of Philosophy.

Sincere appreciation is extended to Dr. Charles B. Beck and Dr. Warren H. Wagner, Jr., for their advice during the course of this research and in the preparation of this manuscript. Appreciation is also extended to the collectors mentioned in Table 1.

2 Current address: Department of Biology, Oberlin College, Oberlin, Ohio. patterns are diverse and often differ among species possessing identical phyllotaxis. In this paper patterns of protoxylem strands of 16 woody ranalean species showing trilacunar and multilacunar nodes are considered. Materials, methods, and terminology utilized here have been discussed in the previous paper.

Observations-Annona muricata, Asimina triloba, Cananga odorata (Annonaceae), $M y$ ristica fragrans (Myristicaceae)-The phyllotaxis and protoxylem strand pattern of vegetative shoots of the three members of the Annonaceae and the single member of the Myristicaceae 